\title{
INTEGRATED AVO, ELASTIC SEISMIC INVERSION AND PETROPHYSICAL ANALYSIS FOR RESERVOIR CHARACTERIZATION: A CASE STUDY OF GAS FIELD, SOUTH SUMATERA BASIN
}

\author{
Abdul Haris $^{1, \mathrm{a})}$, Ressy Sandrina ${ }^{2}$, and Agus Riyanto ${ }^{1}$ \\ ${ }^{1}$ Geology and Geophysics Program, FMIPA Universitas Indonesia, Kampus UI Depok, Indonesia. \\ ${ }^{2}$ Reservoir Geophysics Program, Department of Physics, FMIPA Universitas Indonesia, Kampus UI Depok, \\ Indonesia. \\ Email: a)abdulharis@sci.ui.ac.id
}

\begin{abstract}
Integrated Amplitude Versus Offset ( AVO), elastic seismic inversion and petrophysical analysis have been successfully applied to estimate the elastic parameters of the reservoir for a case study of the gas field in south Sumatera basin. This paper aims to have better understanding the petrophysical properties of the reservoir. The petrophysical analysis was carried out by performing routine formation evaluation that includes calculation of shale volume, porosity, and water saturation of basic good log data. Sensitivity an alysis was conducted to evaluate the sensitivity parameters of the log for changing in lithology, porosity, and fluid content in the reservoir. For completing the availability of elastic parameters from well log data, shear wave logs were derived from Castagna's mudrock line relationship. Further, P-impedance, S-impedance, VpVs ratio, LambdaRho $(\lambda \rho)$, MuRho $(\mu \rho)$ and $\operatorname{density}(\rho)$ were then calculated through a Lambda-Mu-Rho (LMR) transformation. Prior to performing AVO analysis and elastic seismic inversion, super gather technique was applied to improve the reliability of pre-stack seismic data. Elastic seismic inversion was carried out to extract the lateral elastic properties to capture lithology and fluid changes in the reservoir. In addition, AVO analysis of prestacked data was applied to identify hydrocarbon-bearing sandstone at target zone. The petrophysical analysis shows that porosity versus density crossplot is able to distinguish sand-shale based on $34 \%$ shale volume cutoff, while LMR crossplot is able to delineate hydrocarbon zones at water saturation value under $65 \%$. The predicted lateral elastic parameter of the reservoir show's slightly higher value compares to overlying layer. This means the reservoir presents the proper petrophysical properties that associated hydrocarbon gas.
\end{abstract}

Keywords: AVO, elastic seismic inversion and petrophysical analysis, south Sumatera basin.

\section{INTRODUCTION}

There have been numerous optimization strategies has been performed to enhance the productivity of the old producing field of south Sumatera basin. Generally, the integrated application of a $\log$ and seismic data are limited to depth conversion and structural identification. Advanced techniques have been introduced to utilize more of the acquired data [1]. The integrated Amplitude Versus Offset (AVO), elastic seismic inversion and petrophysical analysis is the purposeful strategy for performing rock physics analysis, which is calibrated by laboratory and well measurements and continued to the advanced seismic data processing. In this study, a petrophysical analysis that includes shale volume, 
porosity, and water saturation was performed to identify hydrocarbon bearing zone at the targeted interval.

Petrophysical parameters that can be directly correlated to seismic data is a primary $(\mathrm{P})$ and secondary (S) wave. In this case, $\mathrm{P}$-wave was obtained from a sonic $\log$, while $\mathrm{S}$-wave was derived from Castagna's mudrock line relationship. The sensitivity parameter that was represented by changing of fluid and lithology in the target zone can be observed through various cross plots [2]. Density versus porosity crossplot reflects variation in lithology, where some clean sands demonstrate medium density with high porosity and shales are within the same range but with low porosity [3]. The Lambda-Mu-Rho crossplot gives insight to hydrocarbon presence in reservoir since LambdaRho is the incompressibility expression thus can be used to predict pore fluid content, while Mu-Rho is rigidity term that related to lithology [4].

The elastic seismic inversion, which is known as a simultaneous inversion method, is a process of inverting pre-stack seismic data to estimate elastic impedance ( $\mathrm{P}, \mathrm{S}$ impedance and density). The elastic seismic inversion algorithm is approximated by linearized reflectivity with respect to incidence angle, which is expressed by Aki Richard equation [5]. In this study, the elastic seismic inversion was applied to produce P-impedance, S-impedance, scaled Poison ratio and density section.

The last analysis is AVO responses from pre-stack gather data. This AVO analysis is intended to characterize the AVO response and to infer the type of fluid in the reservoir [5]. In principle, AVO analysis on pre-stack gather data is based on the amplitude response as a function of offset or incidence angle. This means the increasing or decreasing amplitude as a function of angle are associated with petrophysical properties and fluid content [6]. The reflectivitiy coeficient represents elastic parameter change in between an interface. Therefore the conversion of energy causes AVO response at the reflector interface. The AVO response classification is based on different types of lithology and fluid depending responses [7].

\section{METHODS}

The study area is focused on Talang Akar Formation of south Sumatera basin, which is a Tersier back-arc basin located along west to south part of Sunda land. This asymmetric basin bounded by faults and Pre-Tersier sediments to south-west side with Dua Belas Mountains and Tigapuluh Mountains respectively to the north-west and north part of the basin. The basin itself is subdivided into four sub-basin due to compressional and extensional tectonic phase that took place during Cretaceous to Eosen [8]. Talang Akar Formation consists of delta plain sediments with shale, silt, and quartz sandstone and interbedded carbonaceous shale, coals, and some conglomerates [9].

Well, $\log$ data is evaluated to estimate shale volume content, porosity, and water saturation of target zone. Sensitivity analysis was carried to observe the effect of lithology and fluid changes to elastic properties of the reservoir. The detailed reservoir characterization is based on density, porosity, shale volume, acoustic and shear impedance as well as Lambda-Mu-Rho.

Pre-conditioned of prestack seismic data was performed to remove the asymptotic amplitude due to inherent data. In this process, a bandpass filter was applied to pre-stack data were to reduce residual noise. The filtering process is then continued by applying radon parabolic transform to eliminate noise and optimize the primary signal. After that, a super gather was carried to improve the signal to noise ratio. Prior to AVO analysis, the produced super gather was aligned by applying normal moveout correction to prepare prestack seismic data is interpretable.

AVO analysis was carried out by observing the AVO response in terms of AVO gradient (B) and Intercept (A). These AVO attributes were derived from Aki-Richard formula and the plots are characterized based on William Rutherford AVO type. Scaled Poisson's ratio change was also analyzed to identify hydrocarbon presence in the reservoir. Another scheme of AVO classification by Young-Piccollo is used in this analysis. The classifications expand and redefine the commonly used AVO type from Rutherford-Williams and Castagna-Swan. The difference between Young-Piccollo and Rutherford-Williams scheme is in the sand layer, which is designated to be conforming or nonconforming [10]. The conforming sands are re-divided to consider AVO response type 5. The AVO response type is determined based qudrant classification that consider the AVO attributes (intercept and gradient) [10]. 
Prior to performing elastic seismic inversion, the initial earth model was built from well data that was guided by picked horizons. In this study, the elastic seismic inversion used Fatti's version of the Aki-Richard's formula. The algorithm works by approaching reflections amplitude as a function of incident angle [11]. Forward modeling of initial model results in P-impedance (Zp), S-impedance $(\mathrm{Zs})$, and density volume (Dn). Inversion analyses were conducted by matching a regression trend of inversion parameters. The product of elastic seismic inversion is expressed by logarithm of $\mathrm{P}, \mathrm{S}$ impedance and density. Those parameters are derived from linear regression approximation between logarithm of $\mathrm{P}$ and $\mathrm{S}$ impedance and $\mathrm{P}$ impedance and density [12]. This regression then applied to seismic volume to produce inverted Zp, inverted Zs, and inverted Dn. Lithology variation and fluid content of the reservoir can be interpreted from those inverted volumes [13].

\section{RESULTS AND DISCUSSION}

Sensitivity analysis between porosity and density was performed based on log data, which is demonstrated to identify the lithology type of the target zone [14]. The sensitivity is expressed in the crossplot, which is shown in FIGURE 1a. The sand cluster was identified in the density range of 2.25 to $2.45 \mathrm{gr} / \mathrm{cc}$. with porosity is greater than $15 \%$ and shale volume cutoff of $34 \%$. In addition, sensitivity analysis between Lambda-Mu and Lambda-Rho is expressed in the crossplot in the FIGURE 1b. This cross plot is to identify the presence of hydrocarbon in the reservoir. The green area in the crossplot correlates with low water saturation value in the reservoir.

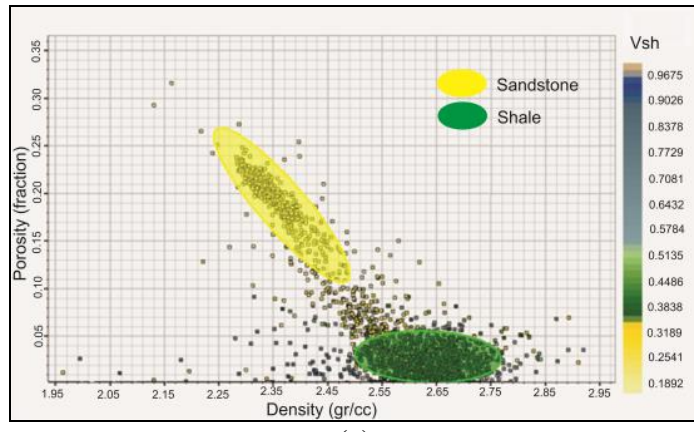

(a)

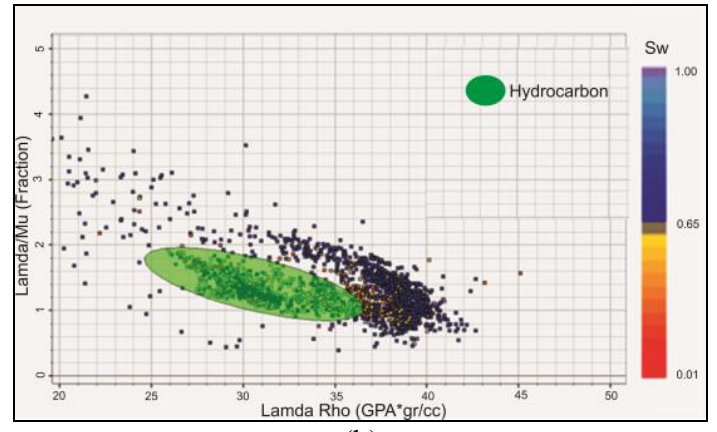

(b)

FIGURE 1. Sensitivity analysis between porosity and density (a) and LMR (b).

The elastic seismic inversion produced P-impedance, S-impedance, and density section, which is illustrated in FIGURE 2. P-impedance section, which is associated with a change of lithology in the target zone, is ranging from 9000 to $10000(\mathrm{ft} / \mathrm{s})^{*}(\mathrm{gr} / \mathrm{cc})$. The targeted zone shows lower Pimpedance than the overlying layer. S-impedance section, which implies rigidity of rocks, is varying from 5000 to $5600(\mathrm{ft} / \mathrm{s}) *(\mathrm{gr} / \mathrm{cc})$. The contrast of S-impedance that related to the fluid content shows light changes may cause by inter-layering of sandstone. In addition, the density section denotes a reservoir with density up to $2.6(\mathrm{gr} / \mathrm{cc})$. In general, the P-impedance and S-impedance expressed a low contrast, while the density section illustrated a high contrast in the target zone. 
(a)

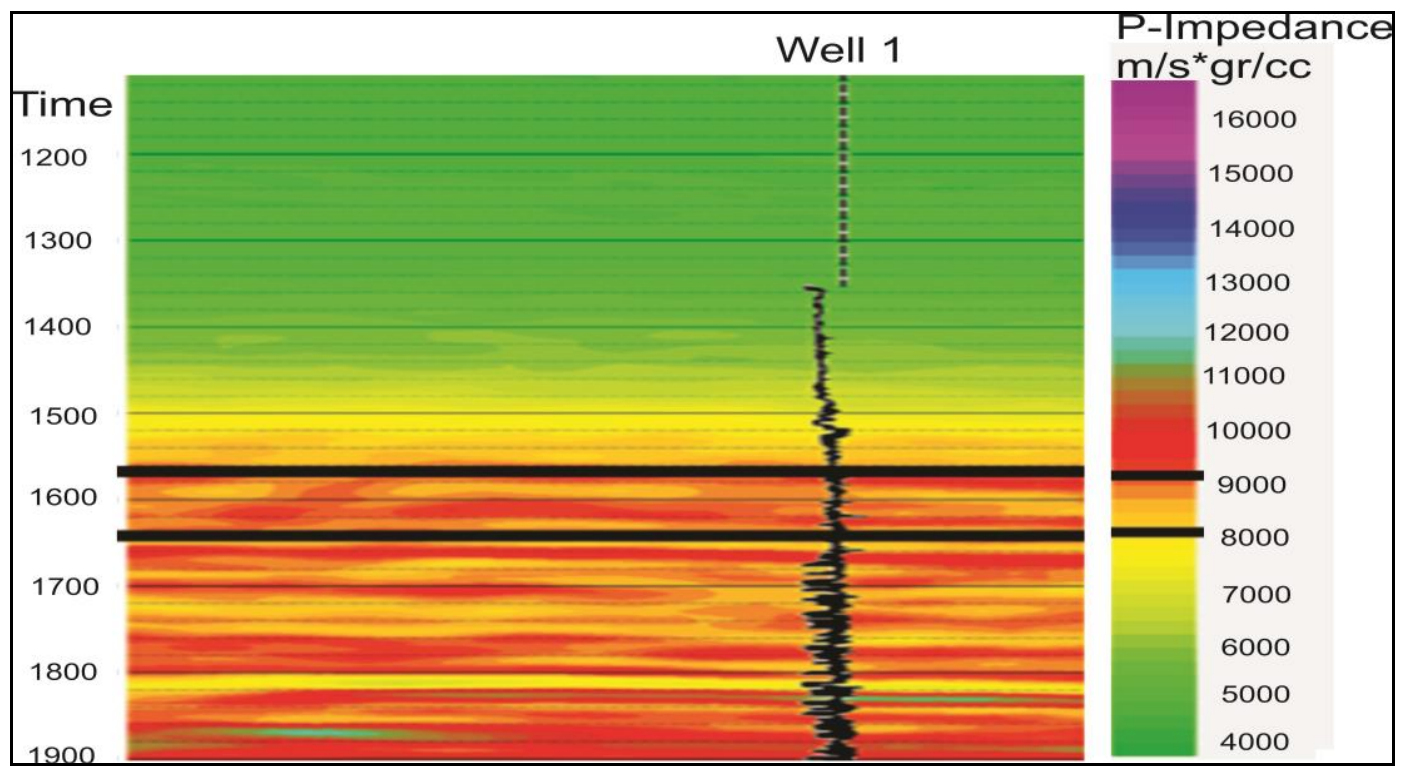

(b)

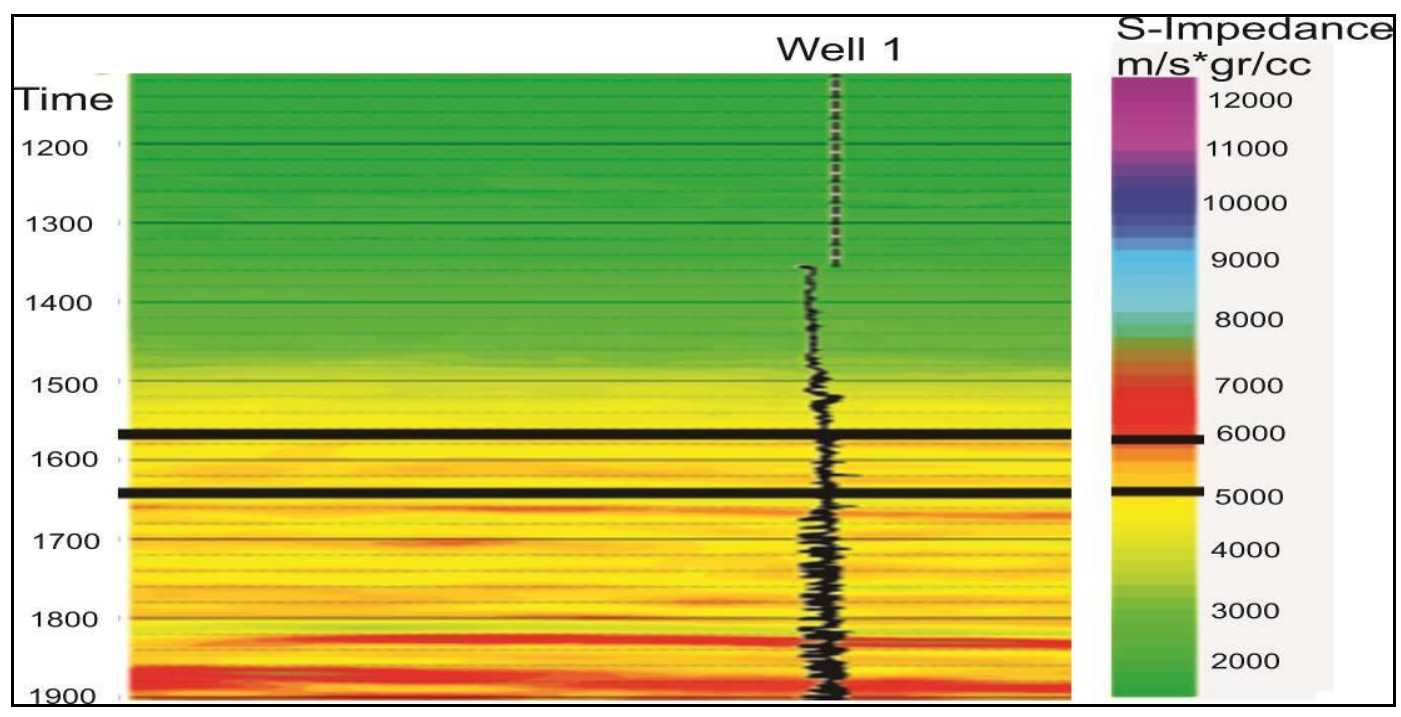

1900

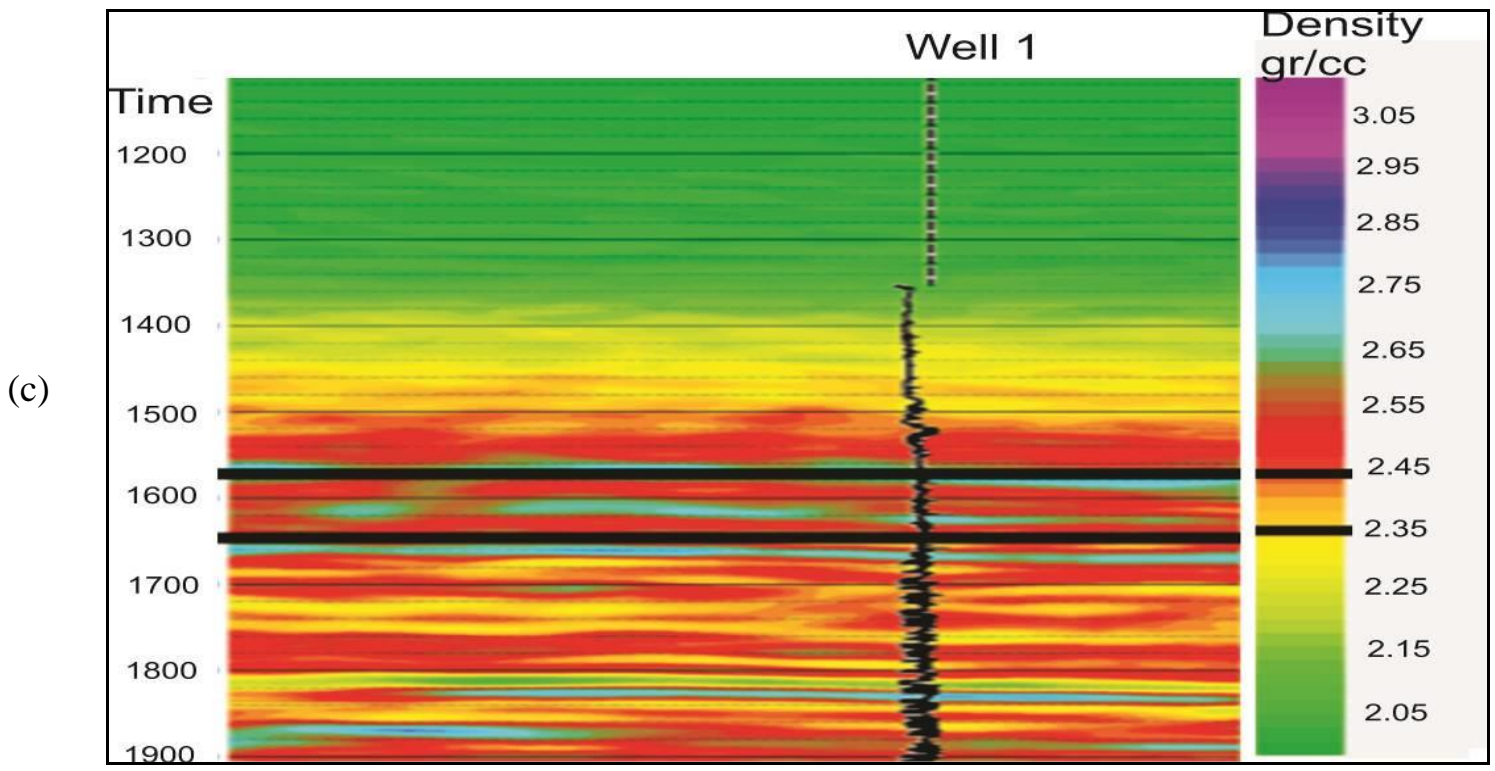

FIGURE 2. Use Inverted section of P-impedance (a), S-impedance (b), and Density (c). 
FIGURE 3 shows the pre-stack seismic data and amplitude curve as a function of offset for the targeted zone. AVO. The seismic reflection event of pre-stack seismic data is identified in the depth of $1650 \mathrm{~ms}$, which is indicated by bright amplitude. The picked amplitude on this reflection event expressed the decreasing amplitude with increasing angle. This AVO response is well known as a dimming event.

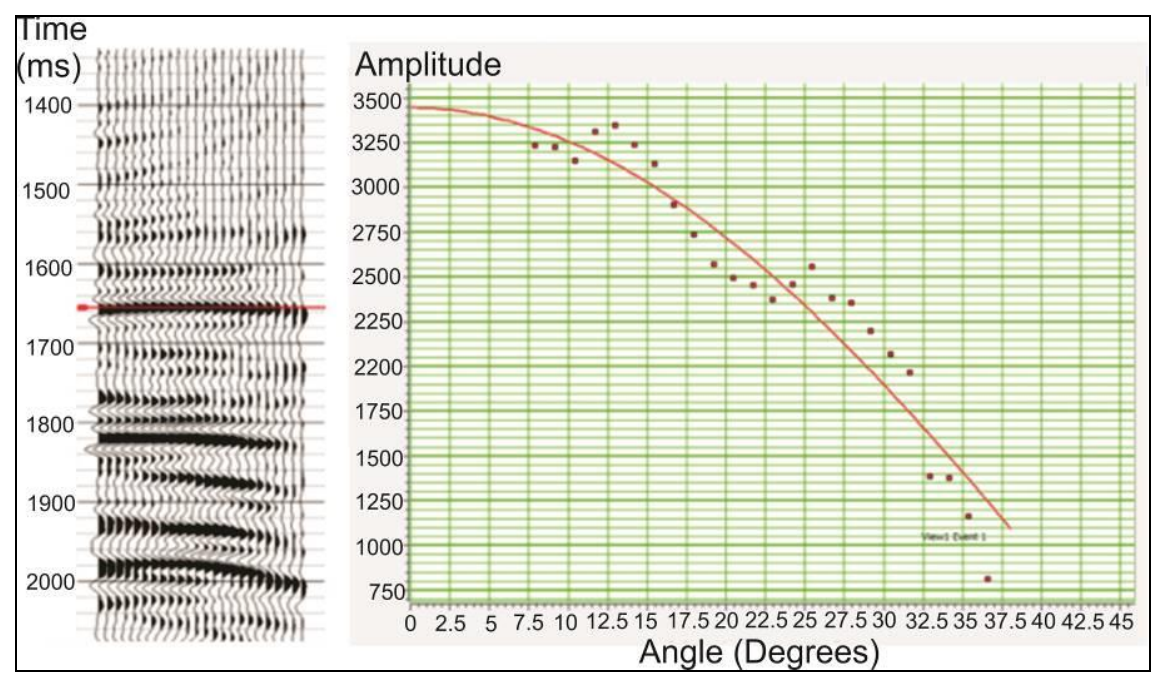

FIGURE 3. Pre-stack seismic data (left) and the amplitude curve as a function of offset for the targeted zone.

FIGURE 4 shows the AVO intercept section. AVO analysis on Intercept (A) section indicates positive value at target zone, this gives insight that impedance is higher than the overlying beds and can be interpreted as lithology changes from sand to shale. Gradient (B) section at target zone has negative value where amplitude at zero offsets is decreasing at far offset.

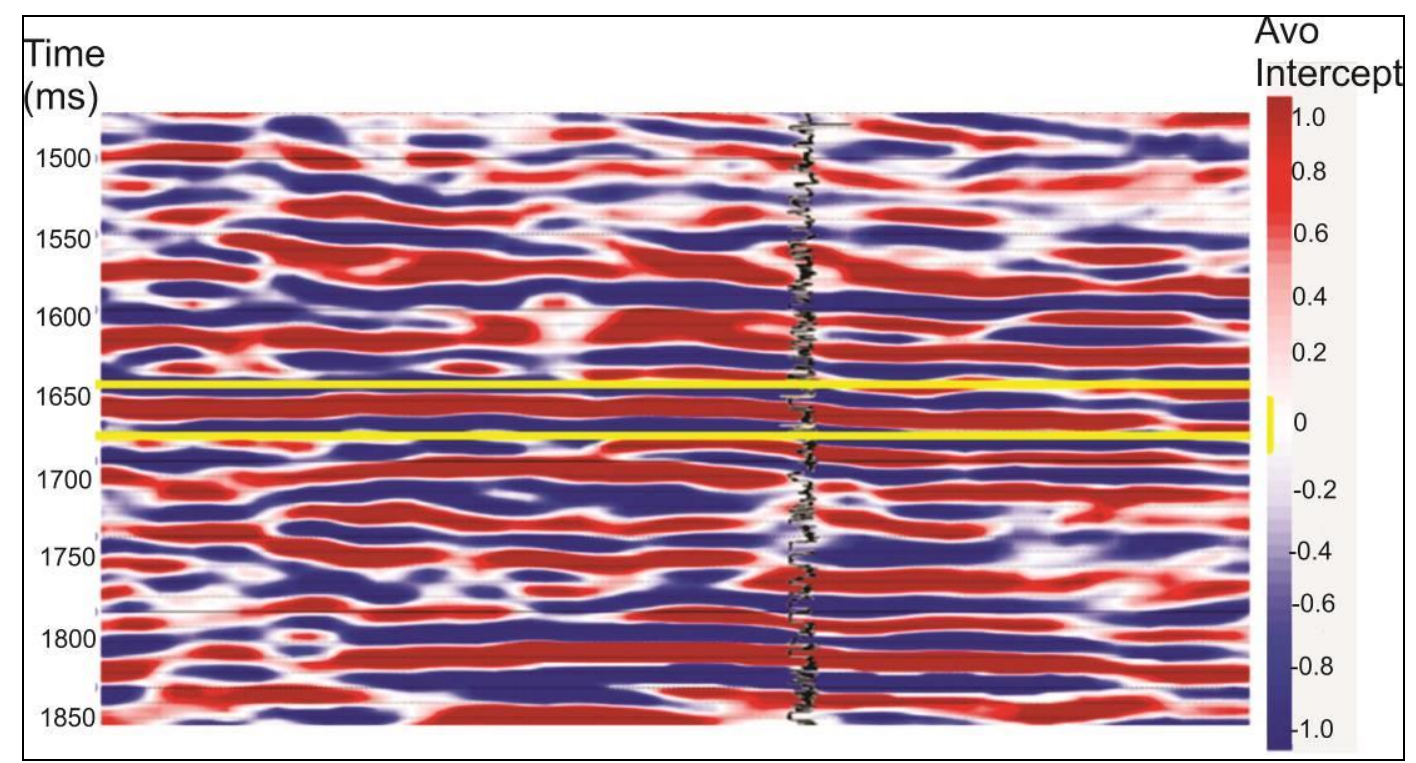

FIGURE 4. AVO intercept section.

AVO analysis on the target zone, which is based on the AVO gradient, illustrated positive amplitude at zero offset and followed by decreasing amplitude with offset. FIGURE 5 shows the AVO gradient section. Refer to William-Rutherford classification this AVO response is classified as a type I. According to Young-Piccollo scheme, this positive intercept and negative gradient, which is 
indicated by decreasing amplitude with increasing offset and no polarity conversion are classified as type -1 of non-conforming sands.

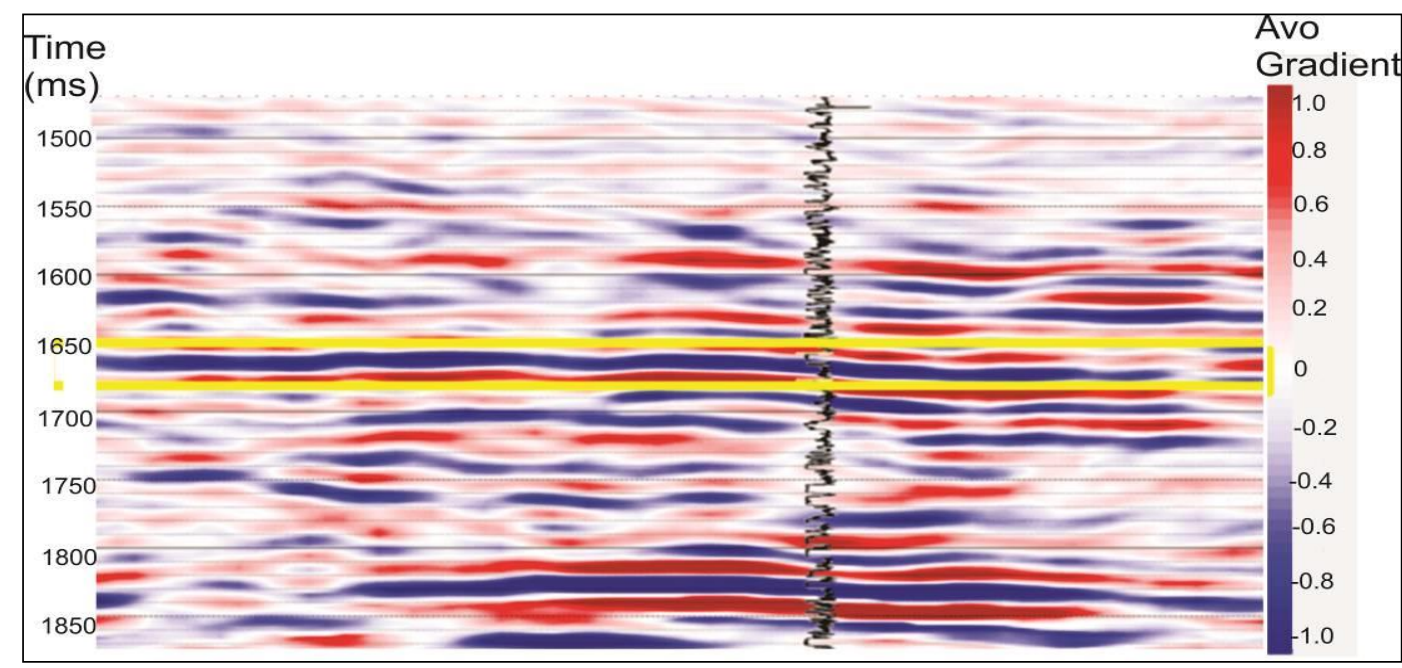

FIGURE 5. AVO gradient section.

The derivation of AVO attribute, which is helpful for identifying the fluid content, is scaled Poisson's ratio [15]. FIGURE 6 illustrates the scaled Poisson's ratio, which is derived from AVO attributes FIGURE 4 and FIGURE 5. The scaled Poisson's ratio on the targeted zone shows strong lateral variation. The scaled Poisson's ratio is ranging from -1 to 1 . The negative Poisson's ratio is associated with the presence of hydrocarbon.

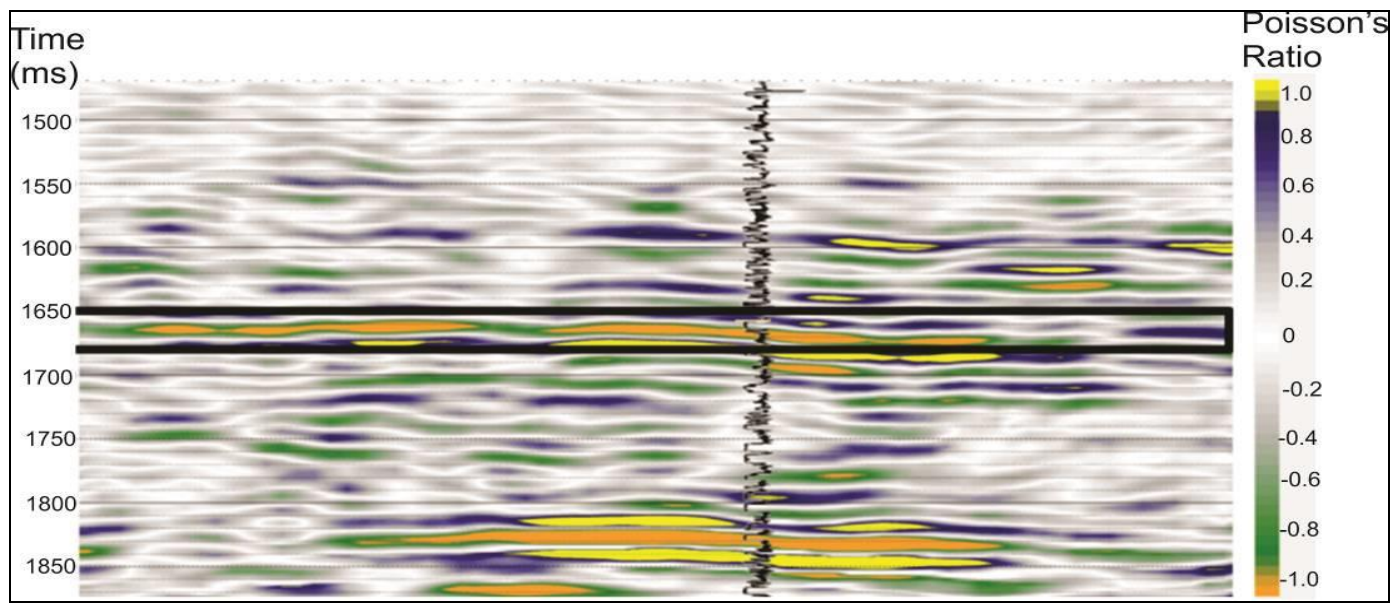

FIGURE 6. Scaled Poisson's Ratio section.

\section{CONCLUSIONS}

Integrated Amplitude Versus Offset ( AVO), elastic seismic inversion and petrophysical analysis have been successfully applied to estimate the elastic parameters of the reservoir for a case study of the gas field in south Sumatera basin. The petrophysical analysis is able to identify the sand reservoir, which is indicated by P-impedance ranging from 9000 to $10000(\mathrm{ft} / \mathrm{s}) *(\mathrm{gr} / \mathrm{cc})$ and S-impedance varying from 5000 to $5600(\mathrm{ft} / \mathrm{s}) *(\mathrm{gr} / \mathrm{cc})$. The elastic parameters have been successfully predicted in the P-impedance, S-impedance and density section, where the targeted zone was indicated by lower elastic impedance. Further, the AVO analysis illustrated that the targeted zone is classified into AVO response type I, which is indicated by decreasing amplitude as a function of offset. Further aplication 
for more detail analysis, this study should be applied to 3D seismic data in order to delineate the reservoir and hydrocarbon gas as well.

\section{REFERENCES}

[1] W. D. Pennington, Seismic petrophysics: An applied science for reservoir geophysics. The Leading Edge, (1997). 16(3), 241-246.

[2] L. A. Gallardo, and M. A. Meju, Joint two-dimensional cross-gradient imaging of magnetotelluric and seismic traveltime data for structural and lithological classification. Geophysical Journal International, (2007). 169(3), pp. 1261-1272.

[3] M. Krief, J. Garat, J. Stellingwerff, and J. Ventre, A petrophysical interpretation using the velocities of $\mathrm{P}$ and $\mathrm{S}$ waves (full-waveform sonic). The Log Analyst, (1990). 31(06).

[4] G. Y. Yang, and R. R. Stewart. Linking petrophysical parameters $(\rho, \sigma, \mu, \lambda, \kappa, \phi)$ with seismic parameters $(\alpha, \beta$, RPP, RPS, RSS). Vol. 7. CREWES Research Report, (Vol. 7, p.1-11), 1997.

[5] D.P. Hampson, B.H. Russell, and B. Bankhead, Simultaneous inversion of pre-stack seismic data. In 2005 SEG Annual Meeting. Society of Exploration Geophysicists (2005, January).

[6] J. P. Castagna, M. L. Batzle, and T. K. Kan. "Rock Physics-The link between rock properties and AVO response, from Offset-dependant reflectivity-theory and practice of AVO analysis, published by the Society of Exploration Geophysicists, edited by Castagna." J, and Backus, M. (1993) p.135 - 171.

[7] J.P. Castagna, and H.W. Swan, Principles of AVO crossplotting. The leading edge, (1997). 16(4), pp.337-344.

[8] A. Pulunggono, S. A. Haryo, and C. G. Kosuma. "Pre-Tertiary and Tertiary fault systems as a framework of the South Sumatra Basin; a study of SAR-maps." p.339-360, (1992).

[9] M. Risyad, I. N. Suta, and A. Haris. "Fault assessment for basement reservoir compartmentalization: a Case study at Northeast Betara gas field, South Sumatra Basin." AIP Conference Proceedings. Vol. 1862. No. 1. AIP Publishing, (2017).

[10] R.A. Young, and R.D. Lo Piccolo, A comprehensive AVO classification. The Leading Edge, (2003). 22(10), pp.1030-1037.

[11] A.M. Dziewonski, and D.L. Anderson, Preliminary reference Earth model. Physics of the earth and planetary interiors, (1981). 25(4), pp.297-356.

[12] R. A. Young, "A technology to extract lithology, porosity and hydrocarbon content from conventional seismic data." (1999).

[13] R. Bornard, F. Allo, Y. Freudenreich, D.H. Caldwell, and J.G. Hamman, Petrophysical Seismic Inversion to determine more accurate and precise reservoir properties. In SPE Europec/EAGE Annual Conference. Society of Petroleum Engineers (2005, January).

[14] G. H. F. Gardner, L. W. Gardner, and A. R. Gregory, Formation velocity and density-The diagnostic basics for stratigraphic traps. Geophysics, (1974). 39(6), pp.770-780.

[15] A. Haris, Y. Nenggala, S. Suparno, R. Raguwanti, and A. Riyanto, Characterization of low contrast shale-sand reservoir using Poisson impedance inversion: Case study of Gumai formation, Jambas field Jambi Sub-basin. In AIP Conference Proceedings (Vol. 1862, No. 1, p. 030188). AIP Publishing (2017, July). 
Volume 3 Issue 1, April 2018
p-ISSN: 2541-3384 e-ISSN: 2541-3392 